\title{
Chuandianella ovata: An early Cambrian stem euarthropod with feather-like appendages
}

\author{
Dayou Zhai, Mark Williams, David J. Siveter, Derek J. Siveter, Thomas H.P. Harvey, \\ Robert S. Sansom, Huijuan Mai, Runqing Zhou, and Xianguang Hou
}

\begin{abstract}
Micro-CT scanning reveals unprecedented three-dimensional soft anatomy of the early Cambrian (Epoch 2, Age 3) euarthropod Chuandianella ovata. We interpret the presence of an elongate, antenniform first appendage, and a short uniramous second appendage, followed by 10 homonomous biramous appendages comprising a short paddle-shaped exopod and a unique feather-like limb-branch with at least 27 podomeres each of which bears a long blade-like endite with a short terminal seta: we interpret this as the endopod. Alternative interpretations, that these limbs might represent an epipod+basipod or epipod+exopod arrangement, are unlikely, in that they would require either the complete reduction of the exopod or the endopod. We also find no evidence for head appendage morphologies that would support a more crownward position, for example among pancrustaceans, that has previously been suggested for C. ovata.
\end{abstract}

Dayou Zhai. Yunnan Key Laboratory for Palaeobiology, Institute of Palaeontology, Yunnan University, 650500 Kunming, Yunnan, China and MEC International Joint Laboratory for Palaeobiology and Palaeoenvironment, Yunnan University, 650500 Kunming, Yunnan, China. dyzhai@ynu.edu.cn Mark Williams. Centre for Palaeobiology Research, School of Geography, Geology and the Environment, University of Leicester, Leicester LE1 7RH, UK and MEC International Joint Laboratory for Palaeobiology and Palaeoenvironment, Yunnan University, 650500 Kunming, Yunnan, China. mri@leicester.ac.uk David J. Siveter. Centre for Palaeobiology Research, School of Geography, Geology and the Environment, University of Leicester, Leicester LE1 7RH, UK and MEC International Joint Laboratory for Palaeobiology and Palaeoenvironment, Yunnan University, 650500 Kunming, Yunnan, China. djs@leicester.ac.uk Derek J. Siveter. Earth Collections, Oxford University Museum of Natural History, Parks Road, Oxford, OX1 3PW, UK and Department of Earth Sciences, University of Oxford, South Parks Road, Oxford OX1 3PR, UK and MEC International Joint Laboratory for Palaeobiology and Palaeoenvironment, Yunnan University, 650500 Kunming, Yunnan, China. derek.siveter@oum.ox.ac.uk

Zhai, Dayou, Williams, Mark, Siveter, David J., Siveter, Derek J., Harvey, Thomas H.P., Sansom, Robert S., Mai, Huijuan, Zhou, Runqing, and Hou, Xianguang. 2022. Chuandianella ovata: An early Cambrian stem euarthropod with feather-like appendages. Palaeontologia Electronica, 25(1):a7. https://doi.org/10.26879/1172 palaeo-electronica.org/content/2022/3557-chuandianella-ovata 
Thomas H.P. Harvey. Centre for Palaeobiology Research, School of Geography, Geology and the Environment, University of Leicester, Leicester LE1 7RH, UK and MEC International Joint Laboratory for Palaeobiology and Palaeoenvironment, Yunnan University, 650500 Kunming, Yunnan, China. thph2@leicester.ac.uk Robert S. Sansom. School of Earth and Environmental Sciences, University of Manchester, Oxford Road, M13 9PT, UK. robert.sansom@manchester.ac.uk

Huijuan Mai. Yunnan Key Laboratory for Palaeobiology, Institute of Palaeontology, Yunnan University, 650500 Kunming, Yunnan, China and MEC International Joint Laboratory for Palaeobiology and Palaeoenvironment, Yunnan University, 650500 Kunming, Yunnan, China. 20179015@ynu.edu.cn Runqing Zhou. Institute of Geology and Geophysics, Chinese Academy of Sciences, 100029 Beijing, China.r.zhou@mail.iggcas.ac.cn

Xianguang Hou. Yunnan Key Laboratory for Palaeobiology, Institute of Palaeontology, Yunnan University, 650500 Kunming, Yunnan, China and MEC International Joint Laboratory for Palaeobiology and Palaeoenvironment, Yunnan University, 650500 Kunming, Yunnan, China. xghou@ynu.edu.cn

Keywords: Chengjiang biota; Cambrian; bivalved arthropod; soft-anatomy; micro-CT; palaeoecology

Submission: 22 June 2021. Acceptance: 4 February 2022.

\section{INTRODUCTION}

During the Cambrian Period bivalved arthropods, such as Chuandianella, formed a numerically abundant and widespread component of marine ecosystems in benthic, nektobenthic, and pelagic settings (e.g., Williams et al., 2007; 2015; Stein et al., 2010; Vannier et al., 2018; Zhai et al., 2019a, $2019 b)$. They are among the most abundant animals in the Chengjiang (Zhao et al., 2012; Hou et al., 2017) and Burgess Shale lagerstätten (Briggs et al., 1994; Caron and Jackson, 2008). Many of these arthropods are species that had been assigned to Bradoriida Raymond, 1935 (see, e.g., Hou et al., 2002) a group common worldwide and with very rare exceptions known only from their bivalved carapaces (Williams et al., 2007). Where bradoriids preserve soft-part anatomy, in many cases conventional classifications based on carapace morphology break down. The markedly different arthropod body plans revealed beneath the bivalved carapace include stem euarthropods (Zhai et al., 2019a), and mandibulates (Aria and Caron, 2017; Vannier et al., 2018) including stem pancrustaceans (Zhai et al., 2019b).

Recent Micro-CT scanning of fossil arthropods has in many cases revolutionised our approach to Cambrian fossil observation and improved access to fine morphological details. This is particularly apparent in the study of the early Cambrian (Epoch 2, Age 3) Chengjiang biota arthropods of China (e.g., Liu et al., 2020), which preserve components of their original three-dimensional soft anatomy including fine details of appendages (e.g., Zhai et al., 2019a, 2019b; Liu et al., 2020). Here we describe newly micro-CT analysed specimens of the Chengjiang bivalved arthropod Chuandianella ovata (Li, 1975), which reveal unprecedented anatomical detail. We undertake a detailed morphological analysis of this new material of $C$. ovata, especially of its appendages, comment on its affinities, and briefly discuss its palaeoecology.

\section{MATERIALS AND METHODS}

New specimens of Chuandianella ovata were collected from the Yu'anshan Member, Chiungchussu Formation, Eoredlichia-Wutingaspis trilobite biozone, Cambrian Series 2, Stage 3, Yunnan Province (see Hou et al., 2017), at Mafang, Ercaicun and Jianshan in Haikou, Kunming (Appendix 1). Fourteen specimens, which revealed appendage morphology in high fidelity, were selected for detailed study. Specimens are mainly housed in the Yunnan Key Laboratory for Palaeobiology (YKLP), Yunnan University, Kunming, and in the Yunnan Geological Survey (Hz-f-4-777, He-f-6-4294).

Fossil structures exposed on the surface of the rock slabs were imaged with a Nikon D3X camera with an Af-S VR105 macro lens and a Keyence VHX6000 stereomicroscope. Fossil structures hidden within the slabs were revealed using a Zeiss Xradia 520 Versa X-ray Microscope. Scanning pixel size ranged from 3.4 to $26.8 \mu \mathrm{m}$, depending on the size of the scanned region and the slab. The digital data from each specimen, in the form of a series of one to a few thousand TIFF images representing cross-sections through different parts of 
the slab, were processed with Drishti software (Version 2.4) to generate 3-D models of the fossils.

\section{SYSTEMATIC PALAEONTOLOGY}

\author{
Phylum Euarthropoda Lankester, 1904 \\ Class incertae sedis \\ Order incertae sedis \\ Family incertae sedis \\ Genus (monotypic) Chuandianella Hou and \\ Bergström, 1991
}

Generic and species diagnosis (amended after Hou and Bergström, 1991). Bivalved euarthropod bearing an antenniform first appendage consisting of at least 10 podomeres; a short, uniramous second appendage with at least six podomeres; and 10 other, homonomous appendages interpreted as comprising a short paddle-shaped exopod and a feather-like endopod bearing at least 27 podomeres each with a long blade-like endite bearing a terminal seta; and an abdomen comprising four apodous segments plus a tailpiece with two elongate, flap-like caudal structures.

Remarks. Alternative interpretations of the homonomous limbs, that they might represent an epipod+basipod or epipod+exopod arrangement, are less parsimonious, in that they would require either the complete reduction of the exopod or the endopod (see further comments in 'Discussion' below).

Type species. Mononotella ovata Li, 1975. Note: The author's name "Li" is spelled "Lee" in some publications.

Type horizon and locality. Chiungchussu Formation, Eoredlichia-Wutingaspis trilobite biozone, Cambrian Series 2, Stage 3. Chiungchussu, Kunming, Yunnan Province, China.

Species. Chuandianella ovata (Li, 1975).

Holotype. Repository given (Li, 1975) as the Institute of Southwestern Geosciences, Chengdu, China (now known as The Chengdu Centre of the Geological Survey of China). Collection number YN6303, specimen number YO10; designated and figured Li, 1975, pl. 3, fig. 16.

Key synonymy. Mononotella ovata Li, 1975, sp. nov., p. 65, pl. 3, figs 16, 17; Mononotella viviosa Li, 1975, sp. nov., p. 65, pl. 3, fig. 18; ?Mononotella marginia $\mathrm{Li}, 1975$, sp. nov., pl. 3, figs 19, 20; Chuandianella ovata (Li, 1975), Hou and Bergström, 1997, p. 41, fig. 37 (q.v. for earlier synonymy); Chuandianella ovata (Li, 1975), Liu and Shu, 2008, p. 358, text-figs 1-3; Chuandianella ovata ( $\mathrm{Li}$, 1975), Hou et al., 2017, p. 238, figs 20.61, 20.62; Chuandianella ovata, Ou et al., 2020, figs 1A, C, E, $\mathrm{G}, \mathrm{H}, \mathrm{J}, 2,3$.

Species diagnosis. As for the genus.
Description. The carapace (a feature termed 'shield' by some) is up to $1.45 \mathrm{~cm}$ long (Liu and Shu, 2008) and is folded along a median line giving a 'bivalved' arrangement; it lacks an articulating hinge. Valves are strongly postplete in lateral outline and lack lobation; they have a narrow incurved free margin (Figures 1A-B, 2A, 3A-B, 4A). In some specimens (Figure 4E, J; Appendix 2A) the external carapace surface is finely pitted. The body is up to $3 \mathrm{~cm}$ long from the anterior sclerite to the proximal part of the tailfans (measured from fig. 1 of $\mathrm{Ou}$ et al., 2020) and consists of 18 segments (Figures $3 B, 5)$. Pedunculate stalked eyes originate from the first (ocular; presumed protocerebral) segment and protrude beyond the anterior margin of the carapace (e.g., Figure 4F-G; Appendices 3, 4). The eye has a dark-coloured central zone and a lightcoloured outer zone, with a well-defined visual surface (Figure 4G; Appendix 4B).

The first appendage is antenniform and consists of at least 10 podomeres; it is narrow, about $30 \%$ longer than the carapace and gradually tapers distally (Figures 1A, 3B, 4A, I; Appendices 4A, 5A). The proximal podomere is stouter than the rest and the more distal podomeres are longer; the inner margin of each podomere bears up to five short stiff adaxially directed setae (Figure 4B-D; Appendix 5). The second appendage is also uniramous, geniculate at about mid-length, and consisting of at least six gradually tapering podomeres; it is presumed to be homologous to an endopod (Figures 1C, E, G, 4K, 5; Appendix 6B-C). Its terminal podomere is elongate, rod-like and apparently lacks a terminal claw (Figures $1 \mathrm{C}, 4 \mathrm{~K}$ ); it is uncertain if it has setae or not. Posterior to the second appendage there are 10 homonomous appendages. Each consists of a short paddle-shaped exopod (Figure 1B, F; Appendices 2C-D, 7A-B, 8A-B) and a much longer endopod that is more robust proximally and gradually tapers distally (Figure $2 \mathrm{C}$ ); evidence of the basipod is not apparent. The endopod bears at least 27 podomeres, each with a long blade-like endite bearing a short terminal seta (Figures 1D, 2C, 4; Appendices 5B, 8C, 9B), giving an overall feather-like appearance to the ramus. The endites in some specimens are preserved perpendicular to the axis of the endopod and parallel to each other (e.g., Figures 1D, 2A), but in other specimens they overlap each other (e.g., Figure 2C) indicating flexible movement and/or taphonomic displacement. The posterior part of the trunk (= abdomen sensu Vannier et al., 2018 and Zhai et al., 2019b), which consists of a tubular section of four sclerites and a tailpiece bearing two long, 


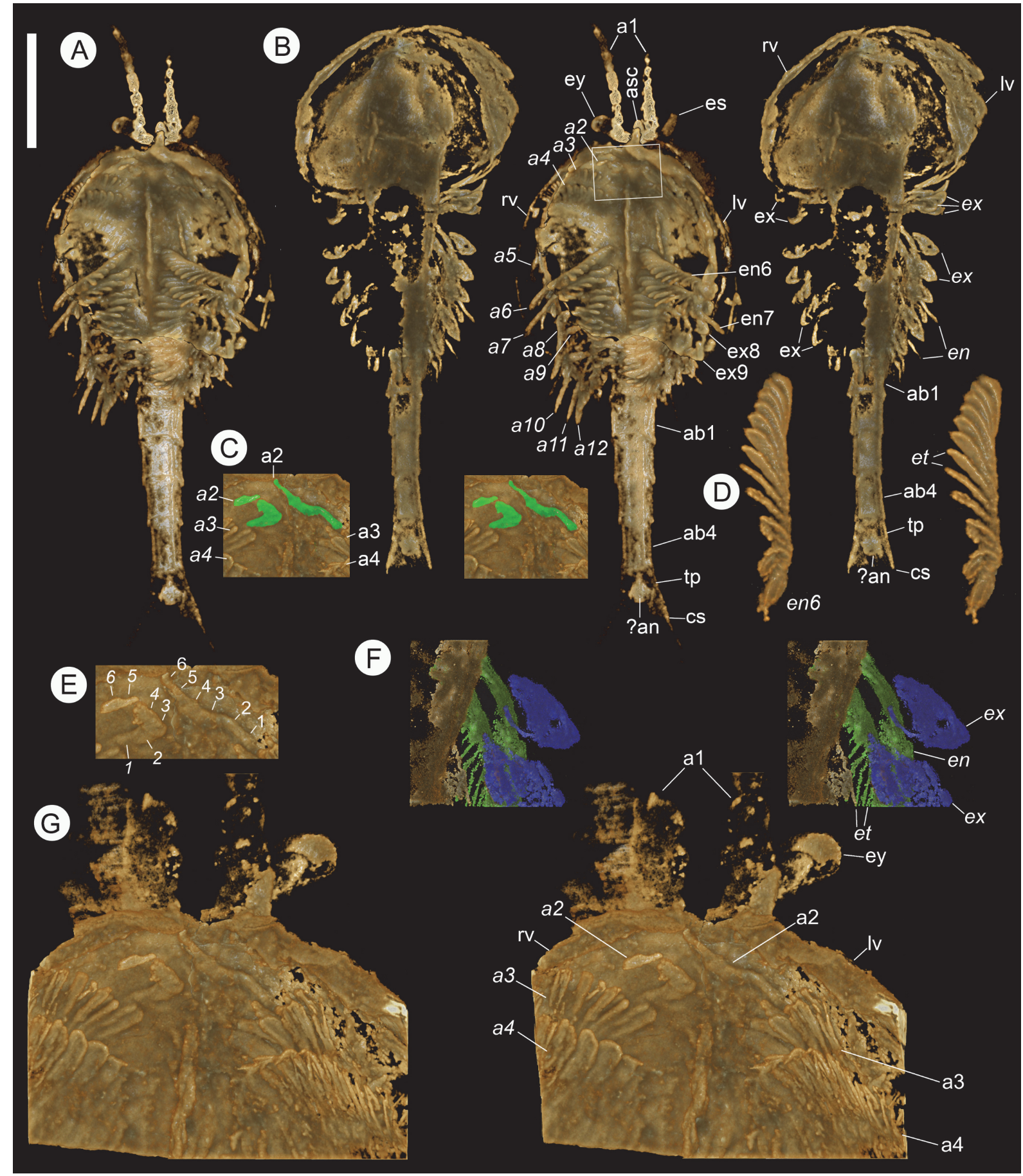

FIGURE 1. Micro-CT images of Chuandianella ovata. (A,C-E,G) YKLP 16218. (A) Ventral view. Scale bar equals 5.0 $\mathrm{mm}$. (C) Ventral view (white rectangle in A), showing details of second appendage (a2, green). Scale bar equals 2.0 $\mathrm{mm}$. (D) Endopod of $6^{\text {th }}$ appendage showing endites. Scale bar equals $1.6 \mathrm{~mm}$. (E) Close-up view of $2^{\text {nd }}$ appendages, with podomeres numbered. Scale bar equals $1.4 \mathrm{~mm}$. (G) Ventral view of the anterior part of $A$, showing the arrangements of the anterior appendages. Scale bar equals $1.3 \mathrm{~mm}$. (B,F) YKLP 16216. (B) Taphonomically deformed specimen, showing ventral view of the carapace and dorsal view of the soft parts (cf. Appendix 7). Scale bar equals $3.8 \mathrm{~mm}$. (F) Dorsal view of part of right side of the body, showing exopods (blue) and endopods (green). Scale bar equals $1.4 \mathrm{~mm}$. All panels except for $\mathrm{E}$ are stereo-pairs. Abbreviations: a1, antenniform first appendage; a2, second appendage; a3-a12, biramous appendages; ab1-4, abdominal segments 1 to 4; an, anus; asc, anterior sclerite; cs, caudal structure; en, endopod; es, eye stalk; et, endite; ex, exopod; ey, stalked eyes; Iv, left valve; rv, right valve; $\mathrm{tp}$, tailpiece. Italics indicate a right-side appendage. 


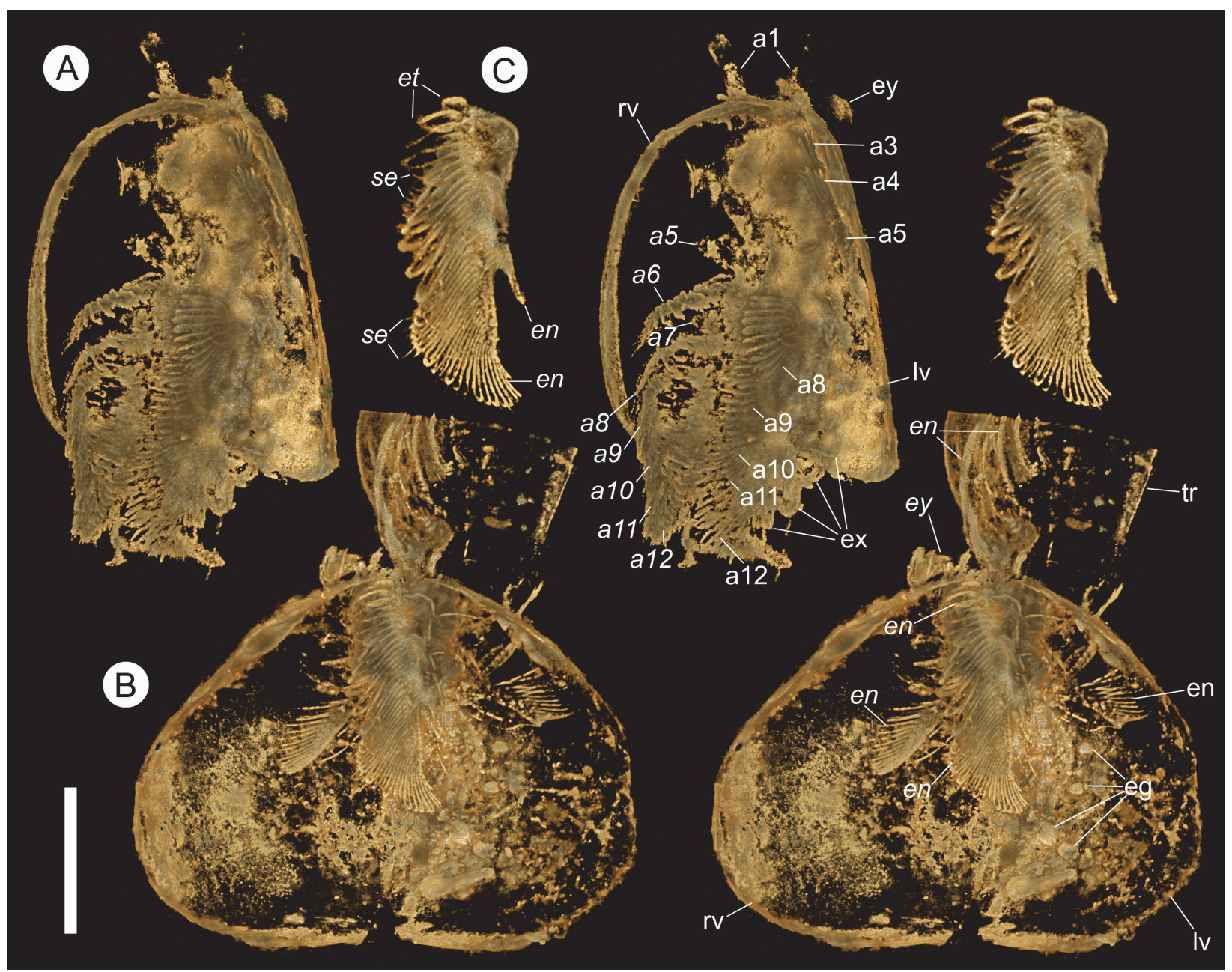

FIGURE 2. Micro-CT images of Chuandianella ovata. (A) YKLP 16238, left lateral view, showing endopods and exopods of trunk appendages. Scale bar equals $4.9 \mathrm{~mm}$. (B,C) YKLP 16239. (B) Ventral view, showing circa 20 eggs within the left valve. Scale bar equals $4.3 \mathrm{~mm}$. (C) Endopods of $3^{\text {rd }}$ and $5^{\text {th }}$ (?) appendages showing long blade-like endites each with a terminal seta. Proximally in this image two endopods overlap, giving the false impression of setae along the lateral margins of the endites. Scale bar equals $3.4 \mathrm{~mm}$. All panels are stereo-pairs. Abbreviations additional to Figure 1: eg, egg; se, seta; tr, trunk. Italics indicate a right-side appendage.

blade-like structures, is apodous (Figures $1 \mathrm{~A}-\mathrm{B}$, $3 A-B)$. The carapace covers about the first nine segments of the body; the more posterior segments protrude posteriorly from the carapace via a gape (Figure 3A-B). Two specimens bear tiny subcircular/ovoid objects, mostly 400-600 $\mu \mathrm{m}$ across and loosely scattered within the left valve (Figure 2B) or roughly arranged in multiple rows (Appendix $10 \mathrm{~A}$ ); they are interpreted as eggs (see Ou et al., 2020). In the better-preserved specimen YKLP 16258 (Appendix 10) at least 48 eggs are associated with a single valve.

\section{DISCUSSION}

\section{Affinities of Chuandianella ovata}

Chuandianella ovata is an 'upper' stem-group euarthropod (sensu Ortega-Hernández, 2016) based on its possession of a multi-segmented head region with, in this case, two pairs of differentiated post-ocular limbs, and complete arthropodization, including post-oral biramous limbs. We cannot determine the presence of a posterior facing mouth beneath a hypostome/labrum complex. Though we cannot see its neurological attachment to the head, we interpret the first appendage pair as deutocerebral in origin based on its position behind the eye and its morphological resemblance 

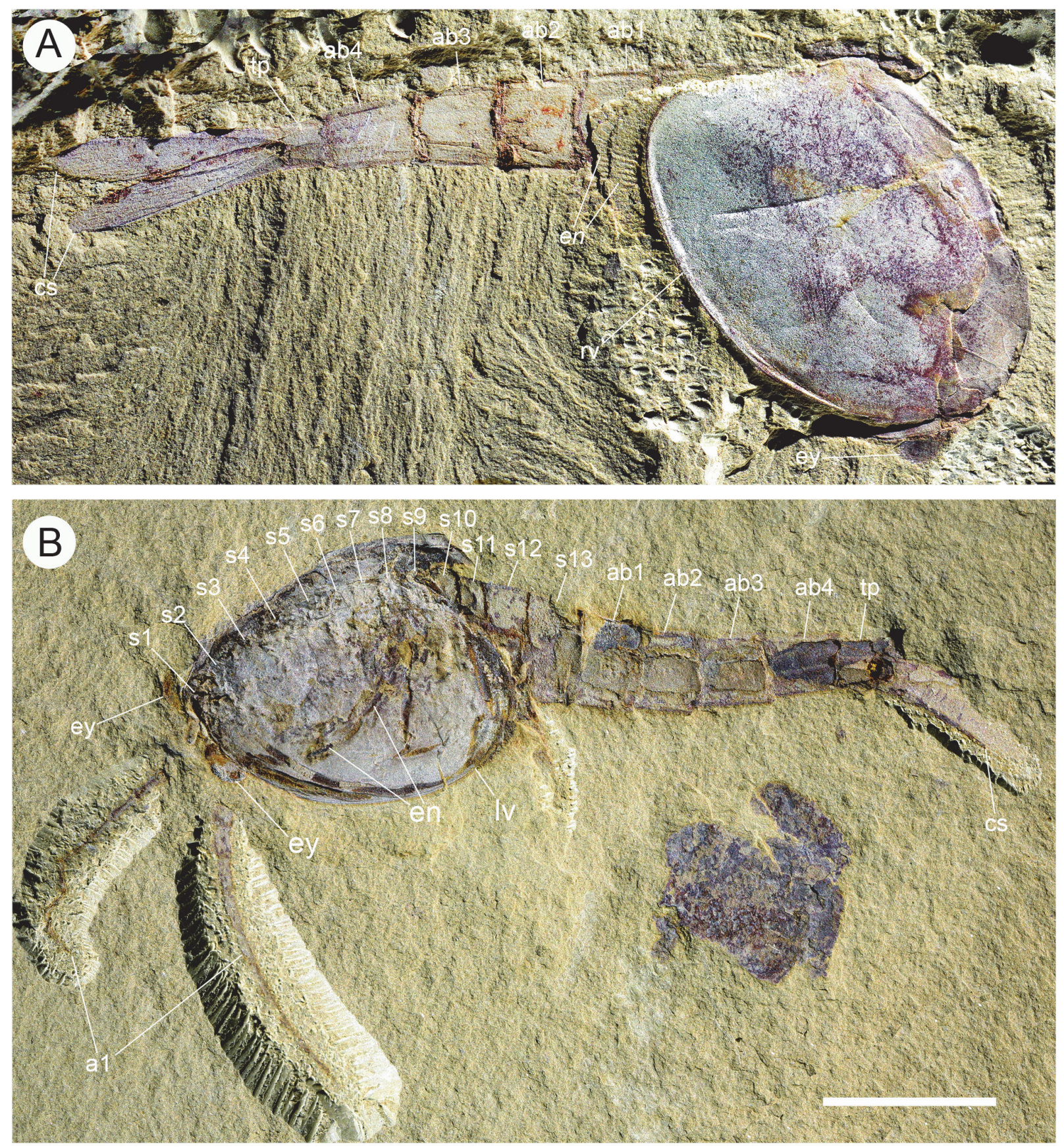

FIGURE 3. Photographs of Chuandianella ovata, showing overall morphology and segmentation of the body. (A) RCCBYU 10272, right lateral view. Scale bar equals $3.4 \mathrm{~mm}$. (B) YKLP 13967a, left lateral view. Scale bar equals 5.0 $\mathrm{mm}$. Abbreviations additional to Figures 1, 2: s1-s12, head and thoracic segments. $\mathrm{s} 1$ is the eye-bearing segment/ anterior sclerite; the position of segments s1 and s2 is difficult to infer. Italics indicate a right-side appendage. Scale bar in (B) applies to both panels.

to the antenniform first appendage of other upper stem group euarthropods.

Based on carapace morphology, Chuandianella ovata was originally (Li, 1975) assigned to the Cambrian bradoriid Mononotella (for which, see Siveter and Williams, 1997) and was subsequently designated (Hou and Bergström, 1991) as the type species of Chuandianella. Chen et al. (1996) and Chen (2004) opined that C. ovata is a waptiid, related to the Burgess Shale Waptia fieldensis Walcott, 1912. Hou and Bergström (1997) tentatively included Chuandianella in the Family Waptii- 

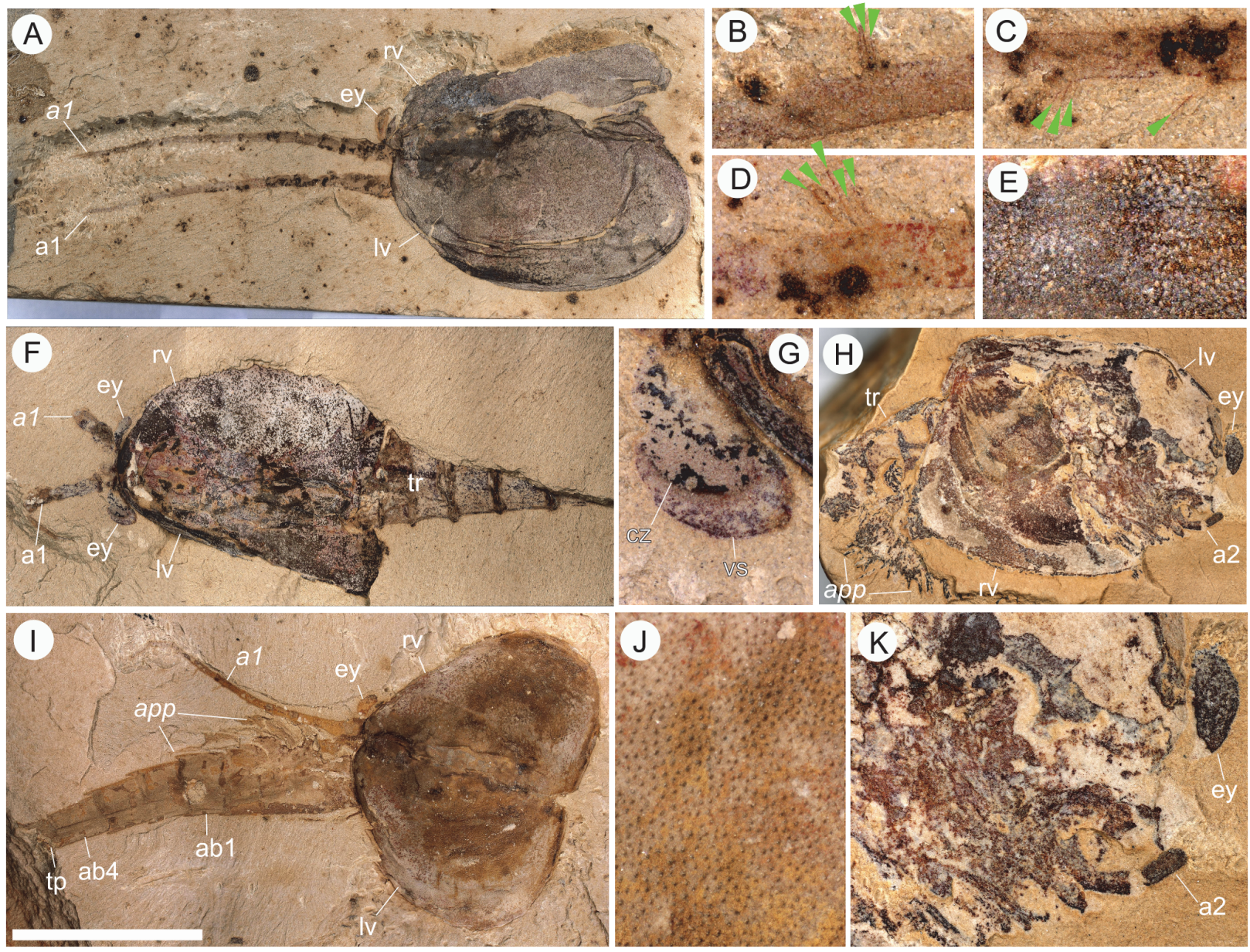

FIGURE 4. Photographs of Chuandianella ovata, showing morphological details. (A-E) YKLP 16217a (cf. Appendix 9). (A) Dorsal view. Scale bar equals $8.3 \mathrm{~mm}$. (B) Setae on inner surface of $7^{\text {th }}$ podomere of left a1. Scale bar equals 0.1 $\mathrm{mm}$. (C) Setae on inner surface of $5^{\text {th }}$ podomere of right antenniform first appendage. Scale bar equals $1.6 \mathrm{~mm}$. (D) Setae on inner surface of $5^{\text {th }}$ podomere of left antenniform first appendage. Scale bar equals $1.3 \mathrm{~mm}$. (E) Pits on carapace surface. Scale bar equals $1.0 \mathrm{~mm}$. (F-G) YKLP 16238a, specimen depicted in Figure 1F. (F) dorsal view. Scale bar equals $8.4 \mathrm{~mm}$. (G) Visual surface of the left eye. Scale bar equals $1.6 \mathrm{~mm}$. $(\mathrm{H}, \mathrm{K}) \mathrm{YKLP}$ 16259, a laterally compressed specimen with anterior part of right valve missing, exposing the anterior appendages. Posterior part of trunk is also missing. $(\mathrm{H})$ Overview. Scale bar equals $6.0 \mathrm{~mm}$. (K) Detailed view of anterior part, showing position and morphology of a2. Scale bar equals $2.4 \mathrm{~mm}$. (I-J) YKLP 16239, specimen depicted in Figure 1G-H. (I) Dorsal view with trunk reflexed so that it appears to emerge from anterior end of carapace. Scale bar equals $8.8 \mathrm{~mm}$. (J) Pits on carapace surface. Scale bar equals $0.9 \mathrm{~mm}$. Abbreviations additional to Figures 1, 2: app, appendage; vs, visual surface. Italics indicate a right-side appendage. Scale bar in (I) applies to all panels.

dae Walcott, 1912, though noted it had 'not yet been studied in detail'. Both taxa have carapaces with a postplete outline lacking lobes and nodes, a dorsal median fold lacking an articulating hinge, a trunk with four apodous segments, and a tailpiece with two caudal structures (Chen et al., 1996; Hou and Bergström, 1997; Chen, 2004). With some exceptions (Liu and Shu, 2004, 2008; Hou et al., 2017) a possible affinity with waptiids has persisted, as in the study of the bivalved Pauloterminus spinodorsalis from the Cambrian of Greenland
(Taylor, 2002) and in Vannier et al. (2018) who considered Chuandianella to be a mandibulate euarthropod. Ou et al. (2020), in their detailed study of the reproductive mode of $C$. ovata assigned it to the pancrustacean Hymenocarina, where the Burgess-Shale $W$. fieldensis is placed. However, the phylogenetic analysis of Ou et al. (2020) did not include key morphologies of Mandibulata such as the presence of mandibles and maxillulae (see the first paragraph of the "Systematic Palaeontology" section as well as table $\mathrm{S} 1$ of $\mathrm{Ou}$ et al., op. cit.). 


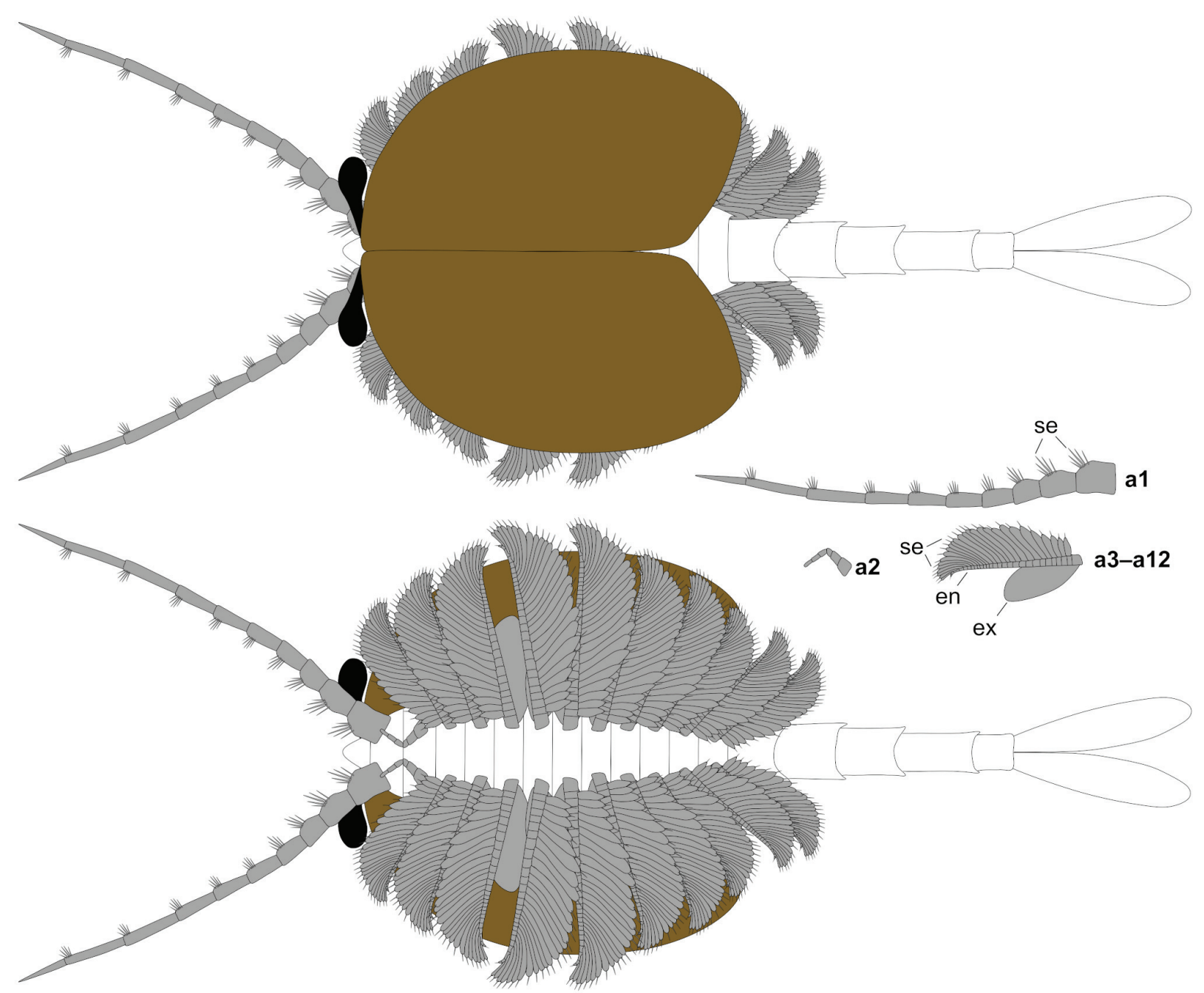

FIGURE 5. Reconstruction of Chuandianella ovata. Upper: dorsal view. Lower: ventral view. Right middle: isolated appendages a1-a3. Not to scale. Abbreviations as in Figures 1-3.

Our detailed CT analysis shows that $C$. ovata does not possess specialized mandibles and maxillulae and therefore should not be assigned to Mandibulata (see also Scholtz and Edgecombe, 2006).

The morphology of Chuandianella ovata is substantially different from both Pauloterminus spinodorsalis and Waptia fieldensis. The biramous trunk appendages of $P$. spinodorsalis, each with a short flagellate endopod consisting of small serial podomeres and a long, paddle-shaped exopod, distinguish it from $C$. ovata, while $P$. spinodorsalis also possesses a longer carapace $(9.1-46.3 \mathrm{~mm}$; Taylor, 2002) compared with that of C. ovata (5.15 $13.09 \mathrm{~mm}$; see Appendix 1). Waptia fieldensis is interpreted as possessing a specialised mandible and maxillula, while the four post-maxillular appendages are also specialized with 5-segmented endopods (Vannier et al., 2018). These diagnostic features, together with the longer carapace of $W$. fieldensis (in adults, $10.99-24.54 \mathrm{~mm}$; Vannier et al., 2018), distinguish it from C. ovata.

A detailed phylogenetic analysis of Chuandianella ovata, pending revision of current phylogenetic databases, will hopefully resolve its relationships to other euarthropods more precisely. The new morphological data provided here will help factor such analyses.

\section{Feather-like endopods of Chuandianella ovata}

Previous studies of Chuandianella ovata (e.g., Liu and Shu, 2008) did not identify the paddleshaped exopods of its trunk limbs, and the featherlike endopods (Figures 1D, 2C, 3A) were interpreted as exopods. The extremely long blade-like endopodal endites of $C$. ovata are remarkable in a Cambrian bivalved euarthropod and further 


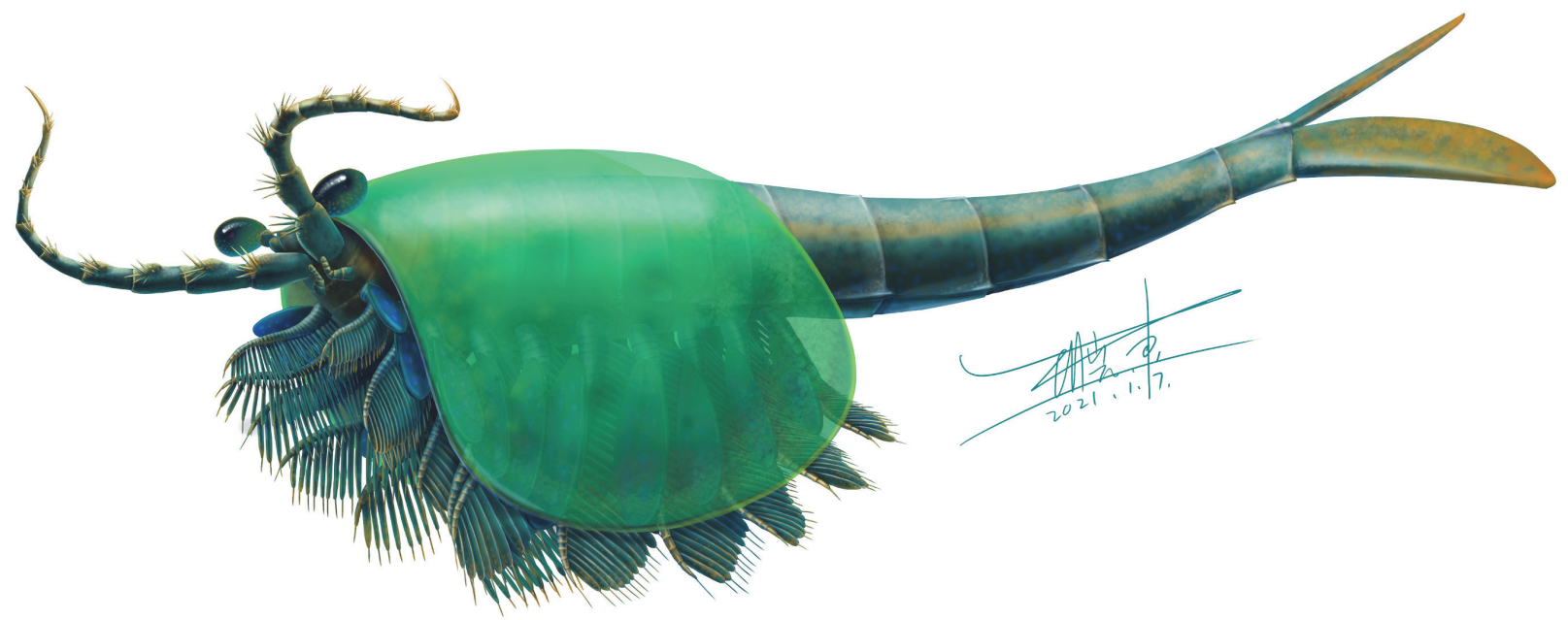

FIGURE 6. Reconstruction of Chuandianella ovata in vivo.

demonstrate that early, 'upper' stem-group euarthropods were experimenting with a wide array of different limb arrangements and morphologies (Zhai et al., 2019a). Morphologically similar structures occur in Waptia fieldensis: six pairs of annulate post-cephalothoracic seemingly singlebranched appendages fringed with long lamellae (Vannier et al., 2018) were interpreted as possible endopods or, more likely, basipods of a unique morphology within Euarthropoda (Vannier et al., 2018). The morphology of the endopods in $C$. ovata also bear comparison with those of the bradoriid Kunmingella douvillei (Mansuy, 1912), though in the latter the endopodal endites are less numerous (see Zhai et al., 2019a), are cylindrical rather than blade-like, and are shorter. Without a full understanding of their 3-D morphology, the endopods of Kunmingella were initially misinterpreted as exopods (Hou et al., 1996, fig. 5).

Alternative interpretations of the homonomous appendage morphology in C. ovata can also be considered. The flap-like outer branch we describe as an exopod might be interpreted as an epipod while the feather-like inner branch might be an extensively modified basipod like that of Waptia (Vannier et al., 2018); or that the limb branch that we interpret as the endopod is morphologically similar to the exopod of Marrella (Briggs et al., 1994) and Misszhouia (Chen and Zhou, 1997). Liu et al. (2021a) identified an additional exite complex consisting of multiple flaps situated proximally to the so-called exopod in different Cambrian arthropods including the megacheiran Leanchoilia illicebrosa and the artiopods Naraoia spinosa and Retifacies abnormalis. This implies that the homol- ogy of the different branches of the arthropod appendages may be complicated, and therefore alternative hypotheses would coexist. In the case of Chuandianella, however, the epipod + basipod/ exopod interpretations are less parsimonious than the exopod + endopod interpretation we favour, in that they would require either the complete reduction of the exopod and the endopod in addition to extensive modification of the basipod (the epipod + basipod interpretation), or the complete reduction of the endopod (the epipod + exopod interpretation). In addition, both 'epipod interpretations' would be accompanied by a crown-ward, possibly pan-crustacean position, of not only Chuandianella but also the bradoriid Kunmingella with its somewhat similar biramous appendages (Zhai et al., 2019a). Such assignments are currently not supported by the morphological evidence that both species lack specialized mandibles and maxillulae.

\section{Mode of life of Chuandianella ovata}

The morphology of the biramous appendages of Chuandianella ovata is not compatible with ambulatory activity on the seabed. The feather-like endopods and well-developed tailpiece of C. ovata may have aided swimming/propulsion and manoeuvrability (Figures 1A, D, 2A, C, 3, 5, 6; see also Liu and Shu, 2008). An ability for wide dispersal is supported by its geographical occurrence: $C$. ovata is relatively common at similar Cambrian stratigraphical levels (Series 2, Stage 3) in Sichuan, Guizhou, and southern Shaanxi provinces, China (Hou et al., 2017), although only material from Yunnan has yielded soft anatomy. The Chinese distribution of $C$. ovata is comparable to bra- 
doriid taxa such as Kunmingella and Liangshanella, which are also known from palaeogeographical regions beyond China (Hou et al., 2002), suggestive of wide dispersal capability. Chuandianella ovata may also have used its long feather-like endopodal endites for filter-feeding, capturing small-sized organic material. Its long setate antenniform first appendages presumably had a sensory function, among other things, perhaps to detect food and monitor environmental conditions and other animals. The diminutive second appendage may have functioned like the main ramus of the first maxillula of living crustaceans such as ostracods (Meisch, 2000) to support food manipulation other than mastication. The welldeveloped stalked eyes protrude beyond the carapace and their preservation in various attitudes suggests that they were mobile to provide multidirectional vision (Figures 1A, 3A-B, 4A, F, I; see also Appendices 3,4 ). The radius of curvature of the eye is greater laterally than frontally, suggesting better resolution of the lateral field (Strausfeld et al., 2016). That C. ovata occurs in supposed coprolites in the Chengjiang biota (Chen and Zhou, 1997; Vannier and Chen, 2005) indicates that it was a prey or carrion item.

The bivalved carapace of Chuandianella ovata, which has recently been shown to be reinforced by phosphatic mineralization (Liu et al., 2021b), functioned not only for protection of soft anatomy but also as a surface for the attachment of its eggs. Ou et al. (2020) reported egg-bearing specimens of $C$. ovata and compared possible reproductive modes of $C$. ovata and Waptia fieldensis (the latter reported by Caron and Vannier, 2016) based on the size, number, and morphology of eggs. They determined that the eggs of $C$. ovata were smaller $(0.5 \mathrm{~mm}$ versus $2.0 \mathrm{~mm}$ in diameter) than those of $W$. fieldensis, but each individual animal carried significantly more eggs ( $\leq 100$ versus $\leq 26$ per clutch) than $W$. fieldensis, implying different reproductive strategies (Ou et al., 2020). Our observations on our egg-bearing specimens of $C$. ovata (Figure 2B; Appendix 10) generally confirm the size, number and position of eggs as indicated by Ou et al. (2020). Since C. ovata is morphologically distinct from $W$. fieldensis differences in brooding strategies between these taxa are not surprising. Sexual dimorphism has been suggested for C. ovata, by which the valves of supposed males are larger, with a greater height to length ratio, and have a pitted rather than smooth surface (Liu and Shu, 2008). As one of the two egg-bearing specimens in our material has pitted valves (Figure 4J) ornament should not be regarded as a possible dimorphic character. We have been unable to replicate the observation (Liu and Shu, 2008) that female and male reproductive systems are preserved in some specimens.

\section{CONCLUSION}

Micro-CT scanning of the stem group euarthropod Chuandianella ovata from the Cambrian Chengjiang Lagerstätte reveals unprecedented details of its soft anatomy. We use these data to interpret $C$. ovata as bearing differentiated first and second appendages, and a further 10 homonomous appendages each bearing a short paddleshaped exopod and a feather-like endopod of at least 27 podomeres. Alternative interpretations, that these limb branches may represent an epipod + basipod or epipod + exopod arrangement, are deemed unlikely. Our interpretation of the limb morphology clearly differentiates Chuandianella from the Cambrian mandibulate euarthropod Waptia, to which it has been compared, and its feather-like endopods attest to the wide diversity of limb arrangements and morphologies developed by early Cambrian, 'upper' stem-group euarthropods. The widespread geographical occurrence of $C$. ovata in the lower Cambrian of southwest China suggests enhanced dispersal capability comparable to that of some contemporaneous bradoriid arthropods. Its well-developed stalked eyes would have provided multi-directional vision for various uses including detection of predators. That $C$. ovata occurs in supposed coprolites in the Chengjiang biota also indicates that it was a prey or carrion item.

\section{ACKNOWLEDGEMENTS}

This study was supported by NSFC grant 41902011, the Key Research Program of the Institute of Geology \& Geophysics, Chinese Academy of Sciences (IGGCAS-201905), and Yunnan Provincial Grants 202101AT070158 and YNWRQNBJ-2019-295. M.W. thanks the Leverhulme Trust for a Research Fellowship (RF-2018-275\4). We thank $X$. Wang for making the artistic reconstruction of Chuandianella used in Figure 6, and Q. Wang for assistance in revising some of the figures. The Jianshan Subsidiary of the Yunnan Phosphate Chemical Group Co. Ltd. provided invaluable help facilitating field work. The Yunnan Geological Survey granted access to two of the specimens. We are grateful for the constructive comments of two anonymous reviewers. 


\section{REFERENCES}

Aria, C. and Caron, J.-B. 2017. Burgess Shale fossils illustrate the origin of the mandibulate body plan. Nature, 545:89-92. https://doi.org/10.1038/nature22080

Briggs, D.E.G, Erwin, D.H., and Collier F.J. 1994. The Fossils of the Burgess Shale. Smithsonian Institution Press, Washington, USA.

Caron, J.-B. and Jackson, D.A. 2008. Paleoecology of the Greater Phyllopod Bed community, Burgess Shale. Palaeogeography, Palaeoclimatology, Palaeoecology, 258:222-256. https://doi.org/10.1016/j.palaeo.2007.05.023

Caron, J.-B. and Vannier, J. 2016. Waptia and the diversification of brood care in early arthropods. Current Biology, 26:69-74. http://doi.org/10.1016/j.cub.2015.11.006

Chen, J. 2004. The Dawn of Animal World. Jiangsu Science and Technology Press, Nanjing, China. (In Chinese)

Chen, J. and Zhou, G. 1997. Biology of the Chengjiang fauna. Bulletin of the National Museum of Natural Science, 10:11-106.

Chen, J.Y., Zhou, G.Q., Zhu, M.Y., and Yeh, K.Y. 1996. The Chengjiang Biota - A Unique Window of the Cambrian Explosion. The National Museum of Natural Science, Taiwan, China. (In Chinese)

Hou, X. and Bergström, J. 1991. The arthropods of the Lower Cambrian Chengjiang fauna, with relationships and evolutionary significance, p. 179-187. In Simonetta, A.M. and Conway Morris, S. (eds.), The Early Evolution of Metazoa and the Significance of Problematic Taxa. Cambridge University Press, Cambridge.

Hou, X. and Bergström, J. 1997. Arthropods of the Lower Cambrian Chengjiang fauna, southwest China. Fossils and Strata, 45:1-116.

Hou, X., Siveter, David J., Williams, M., Walossek, D., and Bergström, J. 1996. Appendages of the arthropod Kunmingella from the Early Cambrian of China: its bearing on the systematic position of the Bradoriida and the fossil record of the Ostracoda. Philosophical Transactions of the Royal Society of London B, 351:1131-1145. https://doi.org/10.1098/rstb.1996.0098

Hou, X., Siveter, David J., Williams, M., and Feng, X. 2002. A Monograph of Bradoriid arthropods from the Lower Cambrian of SW China. Earth and Environmental Science Transactions of the Royal Society of Edinburgh: 92(3):347-409. https://doi.org/10.1017/s0263593300000286

Hou, X., Siveter, David J., Siveter, Derek J., Aldridge, R.J., Cong, P., Gabbott, S.E., Ma, X., Purnell, M., and Williams, M. 2017. The Cambrian Fossils of Chengjiang, China: the Flowering of Early Animal Life. Wiley-Blackwell, Oxford, UK.

Lankester, E.R. 1904. The structure and classification of Arthropoda. Quarterly Journal of Microscopical Science, 47:523-582.

Li, Y.W. 1975. On the Cambrian ostracodes with new material from Sichuan, Yunnan and Shaanxi, China. Professional Papers on Stratigraphy and Palaeontology, 2:37-72. Geological Publishing House, Beijing, China. (In Chinese)

Liu, H. and Shu, D. 2004. New information on Chuandianella from the Lower Cambrian Chengjiang Fauna, Yunnan, China. Journal of Northwest University, 34:453-456. (In Chinese with English summary)

Liu, H. and Shu, D. 2008. Chuandianella ovata from Lower Cambrian Chengjiang biota. Acta Palaeontologica Sinica, 47:352-361.

Liu, Y., Ortega-Hernández, J., Chen, H., Mai, H., Zhai, D., and Hou, X. 2020. Computed tomography sheds new light on the affinities of the enigmatic euarthropod Jianshania furcatus from the early Cambrian Chengjiang biota. BMC Evolutionary Biology, 20:62. https://doi.org/10.1186/s12862-020-01625-4

Liu, Y., Edgecombe, G.D., Schmidt, M., Bond, A.D., Melzer, R.R, Zhai, D., Mai, H., Zhang, M., and Hou, X. 2021a. Exites in Cambrian arthropods and homology of arthropod limb branches. Nature Communications, 12:4619. https://doi.org/10.1038/s41467-021-24918-8

Liu, C., Fu, D., and Zhang, X. 2021b. Phosphatic carapace of the waptiid arthropod Chuandianella ovata and biomineralization of ecdysozoans. Palaeontology, 64:755-763. https://doi.org/10.1111/pala.12570

Mansuy, H. 1912. Pt. 2, Paléontologie. In Deprat, J. and Mansuy, H. (eds.), Etude géologique du Yun-Nan oriental. Mémoires du service géologique de l'Indochine, 1, 146 pp, 7 pls. 
Meisch, C. 2000. Freshwater Ostracoda of Western and Central Europe. In Schwoerbel, J. and Zwick, P. (eds.), Süßwasserfauna von Mitteleuropa 8/3. Spektrum Akademischer Verlag, Heidelberg, Berlin, Germany.

Ortega-Hernández, J. 2016. Making sense of 'lower' and 'upper' stem-group Euarthropoda, with comments on the strict use of the name Arthropoda von Siebold, 1848. Biological Reviews, 91:255-273. https://doi.org/10.1111/brv.12168

Ou, Q., Vannier, J., Yang, X., Chen, A., Mai, H., Shu, D., Han, J., Fu, D., Wang, R., and Mayer, G. 2020. Evolutionary trade-off in reproduction of Cambrian arthropods. Science Advances, 6(18). https://doi.org/10.1126/sciadv.aaz3376

Raymond, P.E. 1935. Leanchoilia and other Mid-Cambrian Arthropoda. Bulletin of the Museum of Comparative Zoology at Harvard University, 76:205-230.

Scholtz, G. and Edgecombe, G. 2006. The evolution of arthropod heads: reconciling morphological, developmental and palaeontological evidence. Development Genes and Evolution, 216:395-415. https://doi.org/10.1007/s00427-006-0085-4

Siveter, David J. and Williams, M. 1997. Cambrian bradoriid and phosphatocopid arthropods of North America. Special Papers in Palaeontology, 57:1-69.

Stein, M., Peel, J.S., Siveter, David J., and Williams, M. 2010. Isoxys (Arthropoda) with preserved soft anatomy from the Sirius Passet Lagerstätte, lower Cambrian of North Greenland. Lethaia, 43:258-265. https://doi.org/10.1111/j.1502-3931.2009.00189.x

Strausfeld, N.J., Ma, X., Edgecombe, G.D., Fortey, R.A., Land, M.F., Liu, Y., Cong, P., and Hou, X. 2016. Arthropod eyes: the early Cambrian fossil record and divergent evolution of visual systems. Arthropod Structure \& Development, 45:152-172. http://doi.org/10.1016/j.asd.2015.07.005

Taylor, R. 2002. A new bivalved arthropod from the early Cambrian Sirius Passet fauna, North Greenland. Palaeontology, 45:97-123. https://doi.org/10.1111/1475-4983.00229

Vannier, J. and Chen, J. 2005. Early Cambrian food chain: new evidence from fossil aggregates in the Moatianshan Shale Biota, SW China. Palaios, 20:3-26. https://doi.org/10.2110/palo.2003.p03-40

Vannier, J., Aria, C., Taylor, R.S., and Caron, J.-B. 2018. Waptia fieldensis Walcott, a mandibulate arthropod from the middle Cambrian Burgess Shale. Royal Society Open Science, 5:172206. http://doi.org/10.1098/rsos.172206

Walcott, C.D. 1912. Middle Cambrian Branchiopoda, Malacostraca, Trilobita and Merostomata. Cambrian Geology and Paleontology II. Smithsonian Miscellaneous Collections, 57:145-288.

Williams, M., Siveter, David J., Popov, L.E., and Vannier, J.M.C. 2007. Biogeography and affinities of the bradoriid arthropods: cosmopolitan microbenthos of the Cambrian seas. Palaeogeography, Palaeoclimatology, Palaeoecology, 248:202-232. https://doi.org/10.1016/j.palaeo.2006.12.004

Williams, M., Vandenbroucke, T., Perrier, V.P., Siveter, David J., and Servais, T. 2015. A link in the chain of the Cambrian zooplankton: bradoriid arthropods invade the water column. Geological Magazine, 152:923-934. https://doi.org/10.1017/S0016756815000059

Zhai, D., Williams, M., Siveter, David J., Harvey, T.H.P., Sansom, R.S., Gabbott, S.E., Siveter, Derek J., Ma, X., Zhou, R., Liu, Y., and Hou, X. 2019a. Variation in appendages in early Cambrian bradoriids reveals a wide range of body plans in stem euarthropods. Communications Biology, 2:329. https://doi.org/10.1038/s42003-019-0573-5

Zhai, D., Ortega-Hernández, J., Wolfe, J.M., Hou, X., Cao, C., and Liu, Y. 2019b. Threedimensionally preserved appendages in an early Cambrian Stem-Group pancrustacean. Current Biology, 29:171-177. https://doi.org/10.1016/j.cub.2018.11.060

Zhao, F., Hu, S., Caron, J.-B., Zhu, M., Yin, Z., and Lu, M. 2012. Spatial variation in the diversity and composition of the Lower Cambrian (Series 2, Stage 3) Chengjiang Biota, Southwest China. Palaeogeography, Palaeoclimatology, Palaeoecology, 346-347:54-56. https://doi.org/10.1016/j.palaeo.2012.05.021 


\section{APPENDICES}

\section{APPENDIX 1.}

Dimensions of specimens of Chuandianella ovata investigated in this study.

\begin{tabular}{llcc}
\hline \multicolumn{1}{c}{ Specimen } & Site & $\begin{array}{c}\text { Carapace length/height } \\
(\mathbf{m m})\end{array}$ & $\begin{array}{c}\text { Body length } \\
(\mathbf{m m})\end{array}$ \\
\hline YKLP 13967 & HM & $8.84 / 6.30$ & 24.51 \\
YKLP 16215 & HE & $7.06 / 4.85$ & $>13.75$ \\
YKLP 16216 & HE & $5.15 / 3.09$ & $18.07-$ \\
YKLP 16217 & HE & $13.09 / 8.22$ & - - \\
YKLP 16218 & HM & $8.15 / 5.13$ & 17.89 \\
YKLP 16238 & HJ & $12.49 / 8.30$ & -- \\
YKLP 16239 & HE & $11.32 / 8.10$ & -- \\
Ch5 & HE & $7.50 / 4.96$ & -- \\
Ch6 & HM & $13.06 / 7.63$ & - \\
Ch11a & HM & $9.77 / 6.95$ & -- \\
Ch12 & HE & $8.97 / 7.40$ & -- \\
RCCBYU 10272 & HM & $7.69 / 5.95$ & 21.53 \\
He-f-6-4-294 & HE & $8.45 / 6.05$ & - \\
Hz-f-4-777 & HE & $7.51 / 4.14$ & -- \\
\hline
\end{tabular}

"A": The sagittal body length is measured from the anterior end of the carapace to the posterior end of the caudal processes. "“": Slightly underestimated value due to incomplete preservation. "- -": The corresponding value is not available. " ": This body-length value is calculated by summing up the carapace length and the length of the body protruding from the valve, in view of the flexed appearance of the body. Abbreviations: HE, Ercaicun of Haikou, Kunming; HJ, Jianshan of Haikou, Kunming; HM, Mafang of Haikou, Kunming. 


\section{APPENDIX 2.}

Chuandianella ovata, YKLP 16256. (A) Microscope image, dorsal vieww. Scale bar equals 0.9 $\mathrm{mm}$. (B) Microscope image, showing pits on left valve. Scale bar equals $0.4 \mathrm{~mm}$. (C-D) Stereopairs of micro-CT images. The posterior part of the body is reflexed so that it emerges from the anterior end of the carapace. Scale bar equals $2.0 \mathrm{~mm}$. (C) Dorsal view. (D) Ventral view. Abbreviations as for Figures 1-4. Italics indicate a right-side appendage. Scale bar in (A) applies to all panels.

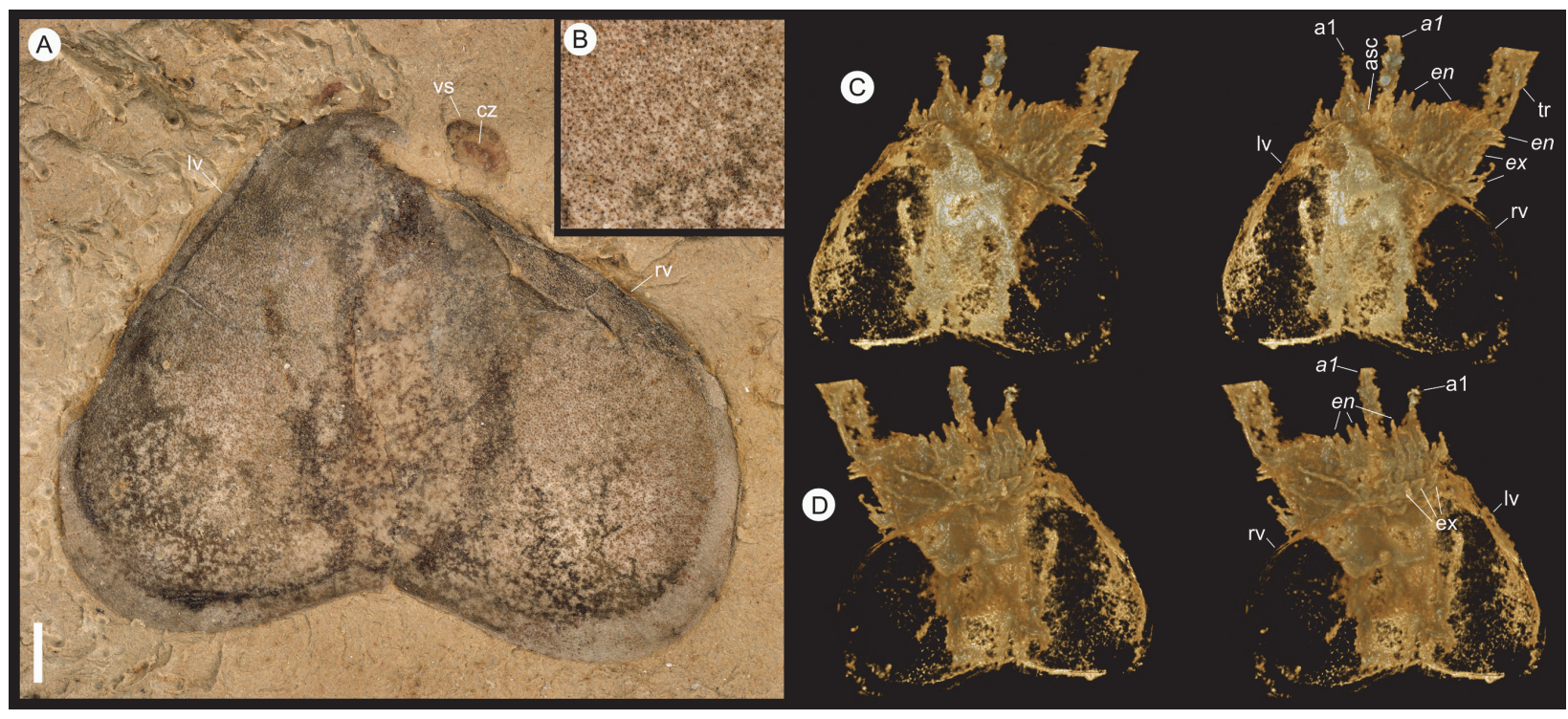




\section{APPENDIX 3.}

Chuandianella ovata, YKLP 16218, microscope images (for micro-CT images of this specimen see Figure 1A, C-E,G). Scale bar equals $1.0 \mathrm{~mm}$. (A) YKLP 16218a, dorsal view of anterior part. (B) YKLP 16218b, ventral view of anterior part; posterior part is buried in sediment. Abbreviations as for Figures 1-4. Italics indicate a right-side appendage. Scale bar in (A) equals $1.0 \mathrm{~mm}$ and applies to both panels.
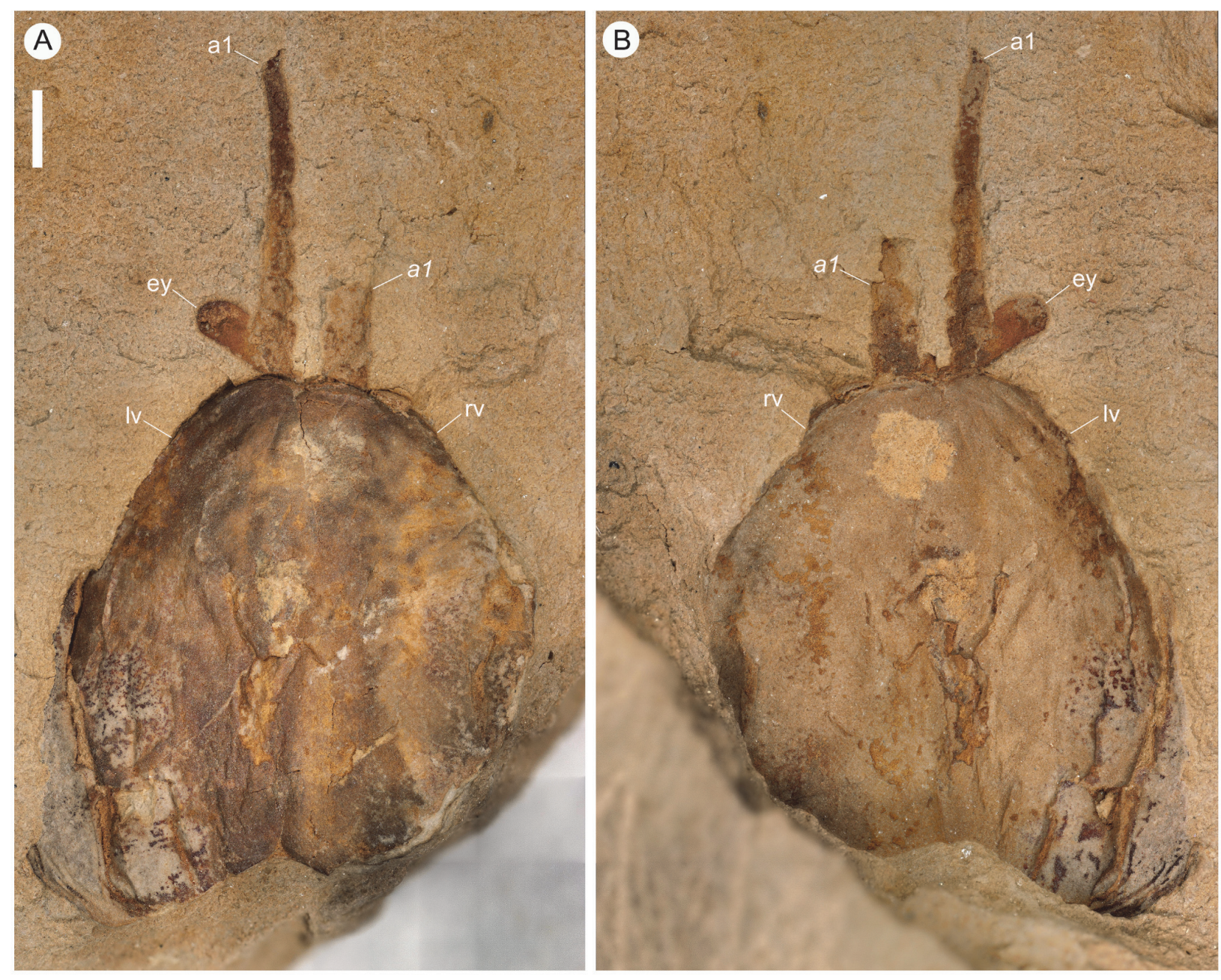


\section{APPENDIX 4.}

Chuandianella ovata, Hz-f-4-777. (A) Microscope image, dorsal view; the left and posterior parts of the specimen are missing. Scale bar equals $1.8 \mathrm{~mm}$. (B) Details of left eye. Scale bar equals $0.7 \mathrm{~mm}$. (C) Stereo-pair of micro-CT image, ventral view of anterior part. Scale bar equals 1.0 $\mathrm{mm}$. Abbreviations as for Figures 1-4. Italics indicate a right-side appendage. Scale bar in (C) applies to all panels.

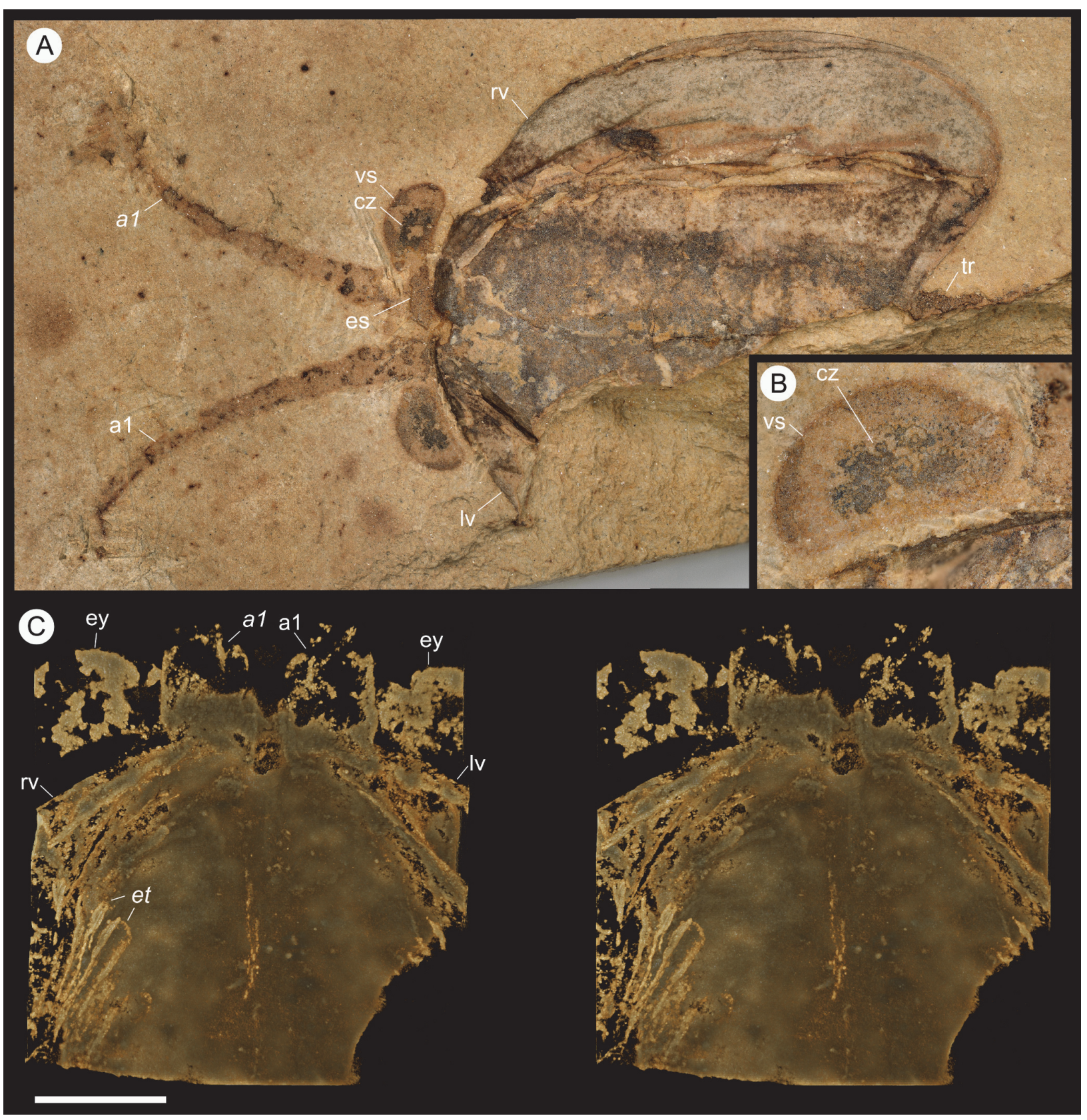




\section{APPENDIX 5.}

Chuandianella ovata, He-f-6-4-294. (A) Microscope image, left view; the posterior part of the trunk is missing. Scale bar equals $1.0 \mathrm{~mm}$. (B) Stereo-pair of micro-CT image, details of anterior part of specimen, oblique-right view (viewed from underside of slab). Scale bar equals $1.2 \mathrm{~mm}$. (C) Details of setae on left a1 (white rectangle in A). Scale bar equals $0.5 \mathrm{~mm}$. Abbreviations as for Figures 1-4. Italics indicate a right-side appendage. Scale bar in (B) applies to all panels.

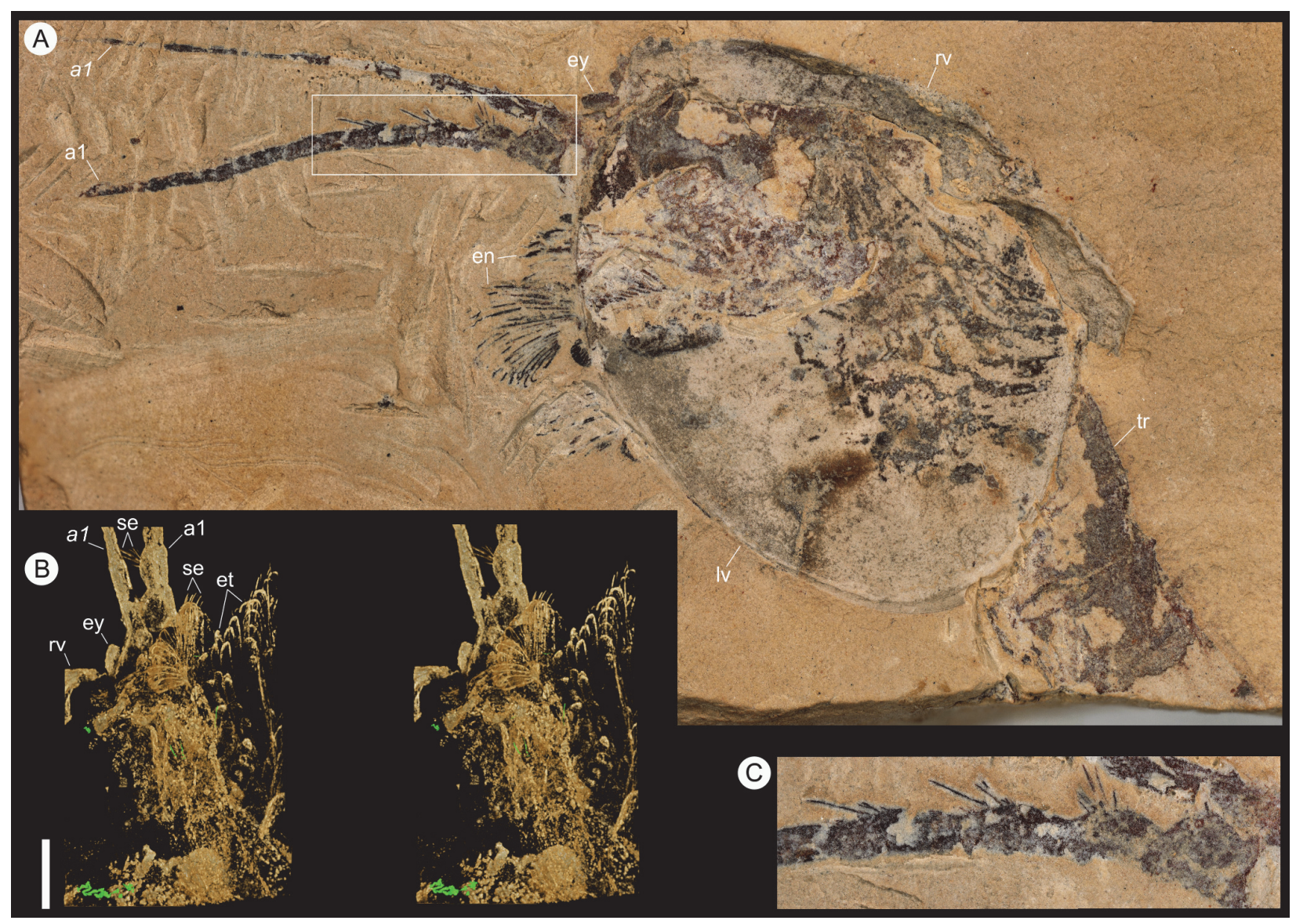




\section{APPENDIX 6.}

Chuandianella ovata, YKLP 16257. (A) Microscope image, dorsal view. Scale bar equals 2.3 $\mathrm{mm}$. (B-C) Stereo-pairs of micro-CT images. (B) Dorsal view. Scale bar equals $5.0 \mathrm{~mm}$. (C) Ventral view of the anterior part (white rectangle in $B$ ), showing a2. Scale bar equals $1.5 \mathrm{~mm}$. Abbreviation additional to Figures 1-4: uf, unidentified fossil. Italics indicate a right-side appendage. Scale bar in (A) applies to all panels.

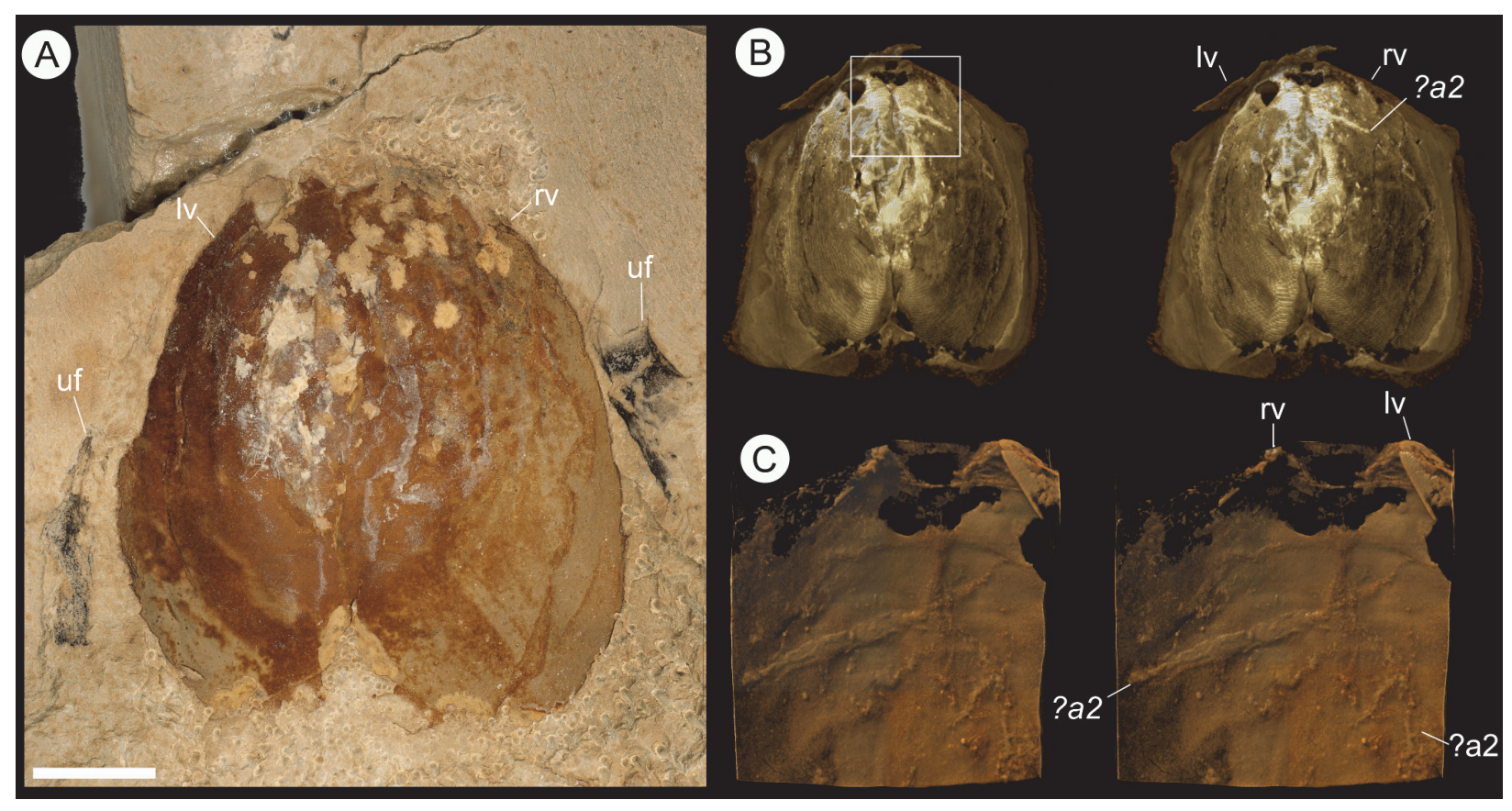




\section{APPENDIX 7.}

Chuandianella ovata, YKLP 16216. (A) Microscope image of specimen on rock slab. Scale bar equals $0.8 \mathrm{~mm}$. (B) Micro-CT stereopair image. Scale bar equals $2.0 \mathrm{~mm}$. Abbreviations as for Figures 1-4. Note: The soft parts of this specimen are taphonomically dislocated and are flipped vertically, so that this figure shows the dorsal views of the carapace and the ventral views of the trunk and appendages, with the left appendages associated with the right valve while the right appendages are associated with the left valve (cf. Figure 1B, G). Italics indicate a right-side appendage. Scale bar in (B) applies to both panels.

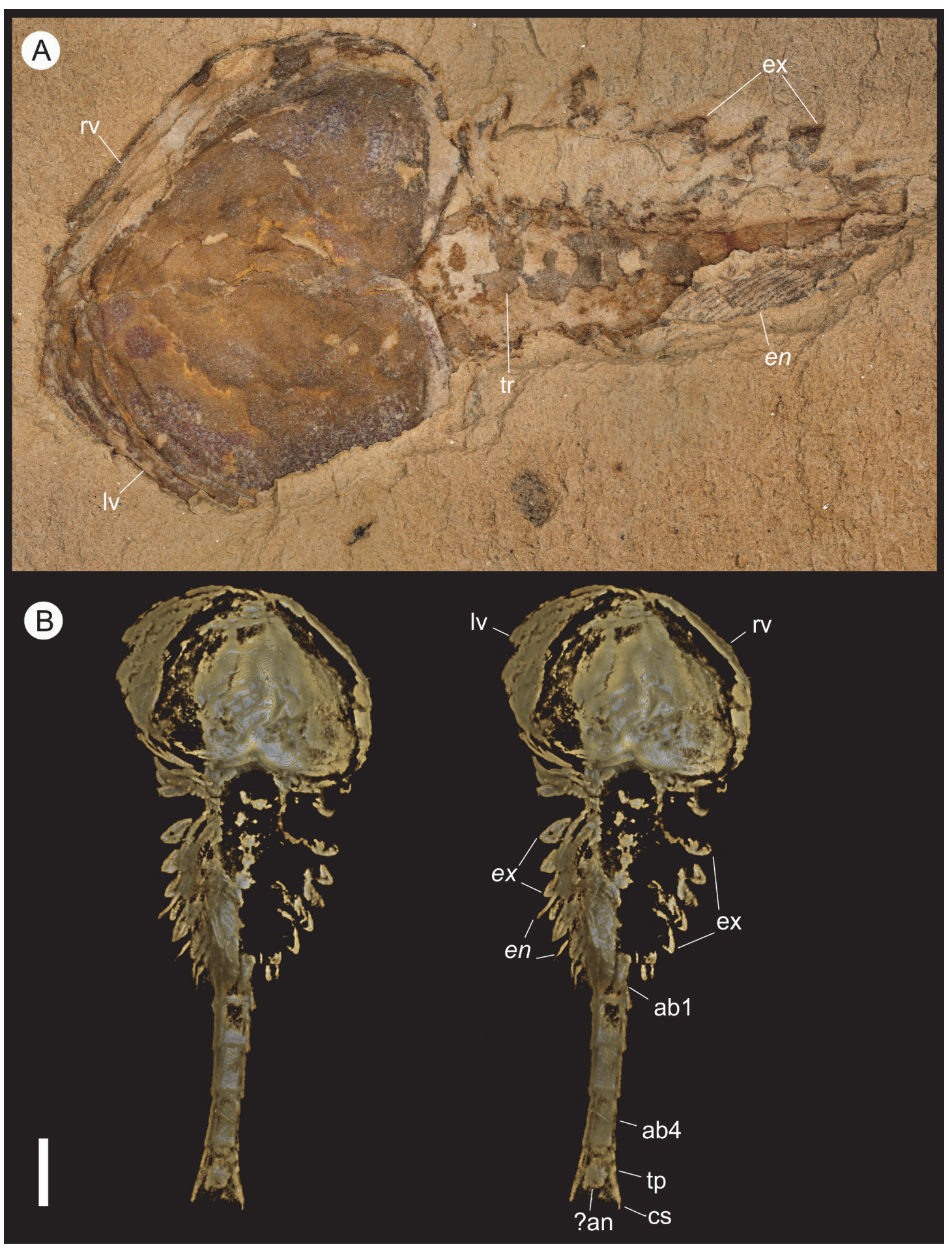




\section{APPENDIX 8.}

Chuandianella ovata, YKLP 16215a. (A) Microscope image of specimen on rock slab, dorsal view. Note that the posterior part of the trunk is missing. Scale bar equals $3.3 \mathrm{~mm}$. (B-C) MicroCT images of anterior part, stereo-pairs (anterior end to the left). Scale bar equals $3.1 \mathrm{~mm}$. (B) Dorsal view. (C) Ventral view. Abbreviations as for Figures 1-4. Italics indicate a right-side appendage. Scale bar in (A) applies to all panels.

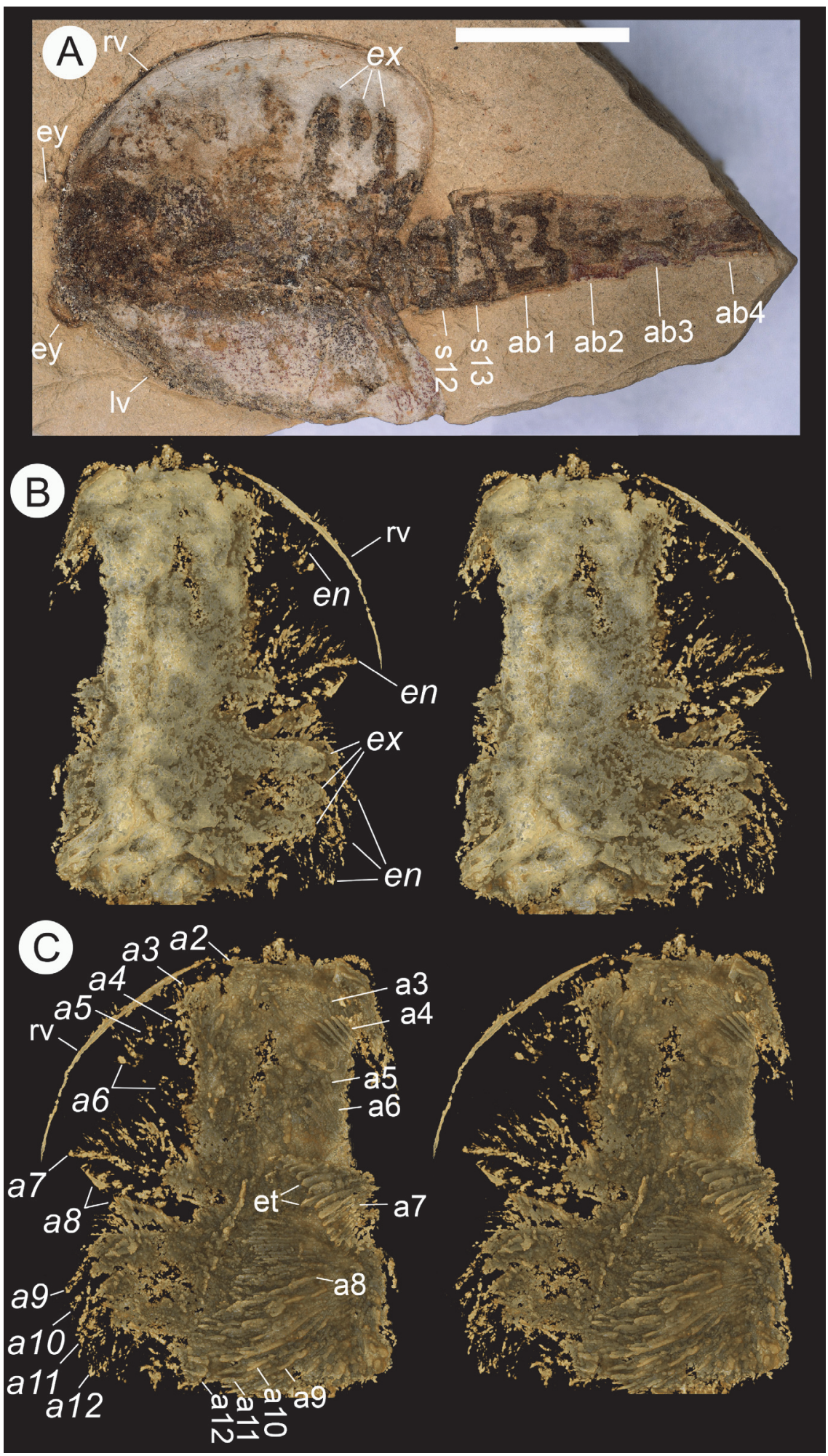




\section{APPENDIX 9.}

Chuandianella ovata, YKLP 16217 (for microscope image of this specimen see Figure 4A-E), stereo-pairs of micro-CT images. Scale bar equals $5.0 \mathrm{~mm}$. (A) Dorsal view of anterior part. (B) Ventral view of anterior part. Italics indicate a right-side appendage. Scale bar in (A) equals 5.0 $\mathrm{mm}$ and applies to both panels.

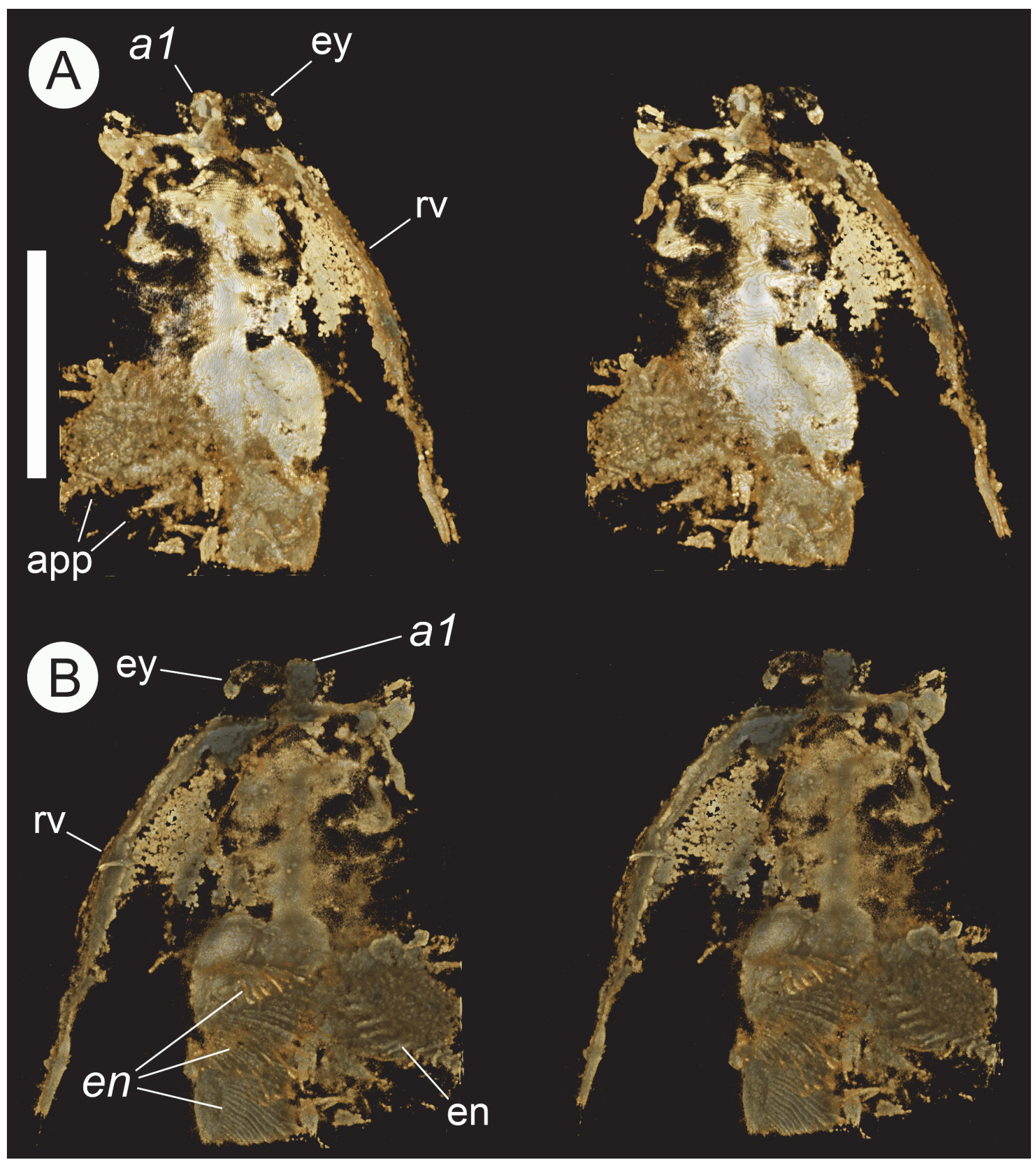




\section{APPENDIX 10.}

Chuandianella ovata, YKLP 16258, an egg-bearing specimen, microscope images. (A) Overview, oblique-right view. Scale bar equals $2.0 \mathrm{~mm}$. (B) Details of eggs (white rectangle in A). Scale bar equals $1.4 \mathrm{~mm}$. Abbreviations as for Figures 1-4. Italics indicate a right-side appendage. Scale bar in (A) applies to both panels.

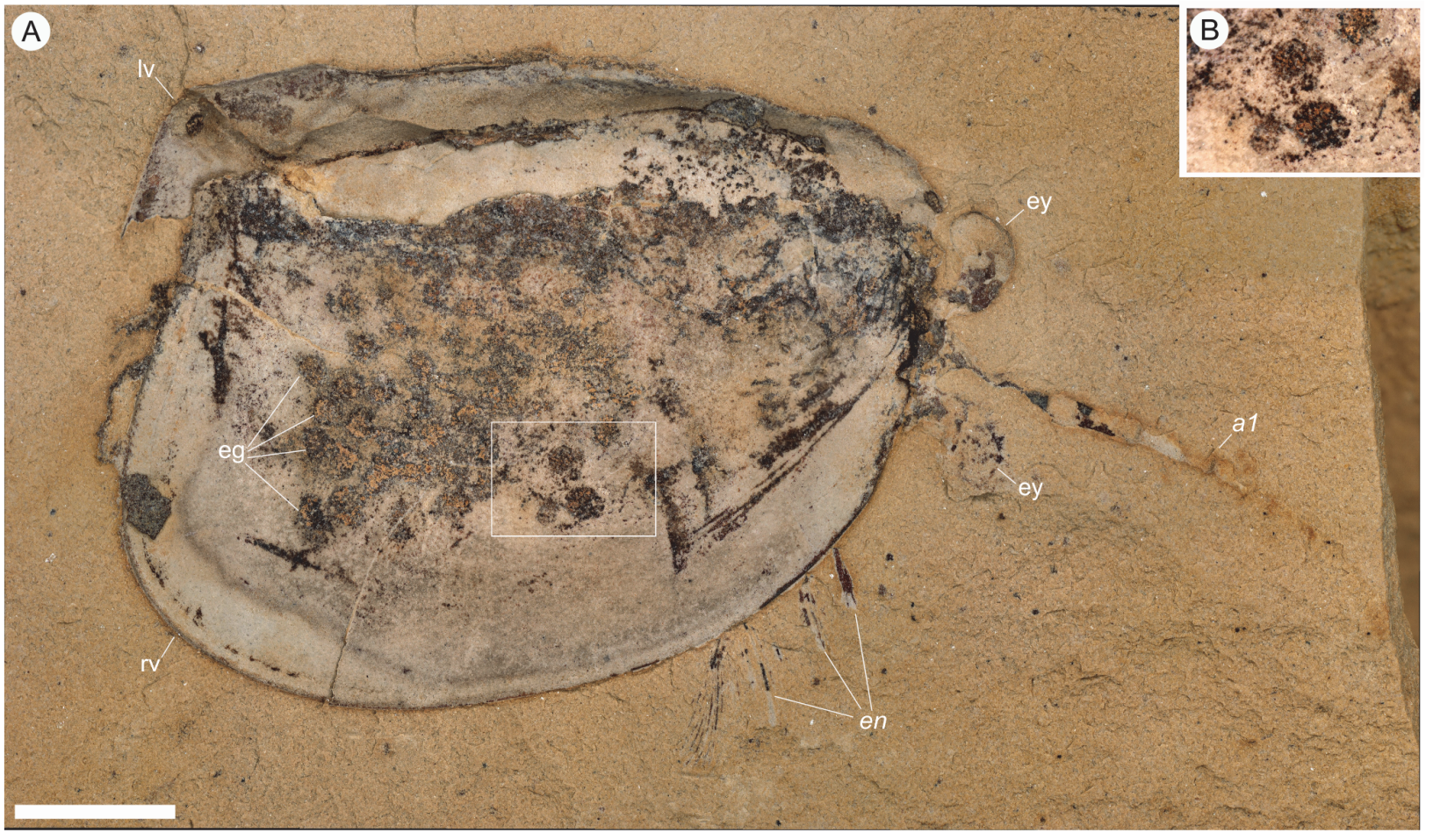

